Rhode Island College

Digital Commons @ RIC

Master's Theses, Dissertations, Graduate

Master's Theses, Dissertations, Graduate Research and Major Papers Overview

Research and Major Papers

$5-2017$

\title{
Interprofessional Simulation: Students' Perceptions
}

Elizabeth Katherine Welch

Rhode Island College

Follow this and additional works at: https://digitalcommons.ric.edu/etd

Part of the Other Nursing Commons

\section{Recommended Citation}

Welch, Elizabeth Katherine, "Interprofessional Simulation: Students' Perceptions" (2017). Master's Theses, Dissertations, Graduate Research and Major Papers Overview. 178.

https://digitalcommons.ric.edu/etd/178

This Major Paper is brought to you for free and open access by the Master's Theses, Dissertations, Graduate Research and Major Papers at Digital Commons @ RIC. It has been accepted for inclusion in Master's Theses, Dissertations, Graduate Research and Major Papers Overview by an authorized administrator of Digital Commons @ RIC. For more information, please contact digitalcommons@ric.edu. 

INTERPROFESSIONAL SIMULATION: STUDENTS' PERCEPTIONS

A Major Paper Presented

by

Elizabeth Katherine Welch

Approved:

Committee Chairperson

(Date)

Committee Members

(Date)

(Date)

Director of Master's Program

(Date)

Dean, School of Nursing 
INTERPROFESSIONAL SIMULATION: STUDENTS' PERCEPTIONS

by

Elizabeth Katherine Welch

A Major Paper Submitted in Partial Fulfillment

of the Requirements for the Degree of

Master of Science in Nursing

in

The School of Nursing

Rhode Island College

2017 


\begin{abstract}
An alarming number of errors occur in the healthcare system. The Institute of Medicine (IOM) responded to the error rate by encouraging changes in professional education and recommending interdisciplinary team training. A variety of professions, including aviation and the military, have utilized simulation in their education and training for mastering skills and also to assist with respect and appreciation of other professional roles on the healthcare team. The purpose of this study was to examine undergraduate nursing students, graduate social work students, and APRN students' perceptions of one another as healthcare professionals using interdisciplinary simulation. The research study was a quantitative descriptive study using a pre-test, intervention, post-test design with a nonprobability, convenience sample. The participants were asked to complete the IEPS questionnaire, an eighteen-question survey with a 6-point Likert scale that measures the effect of interprofessional education experiences on students. The participants then took part in four interprofessional simulations scenarios with debriefing sessions following each scenario. The same IEPS was completed at the end of the day. 109 participants from the mentioned disciplines participated in the study. Statistically significant higher scores were found on the posttest questionnaires in 17 of the 18 questions. The study supports the use of interprofessional simulation in higher education and also provides a proven benefit related to perceptions of other disciplines.
\end{abstract}




\section{Acknowledgements}

I would like to begin by thanking the many great faculty members of the Rhode Island College School of Nursing that have assisted me not only in this writing of this paper, but also throughout my time in the graduate program. Additionally, Patricia Calvert, thank you for all of your assistance with the proposal and your timely and well thought out feedback. To my first reader, Dr. Debra Servello, without your thorough edits and suggestions along with your constant encouragement, I never would have completed this project. Your dedication not only to your students, but also to the program have certainly not gone unnoticed. I thank you from the bottom of my heart for all that you do and have done! Dr. Judy Murphy, thank you for all of your simulation wisdom, not only for this paper, but also in class. Your passion for simulation is amazing. Many thanks to Dr. David Lindquist, MD for taking on task of being my third reader despite not being familiar with the role. The time that you spent helping me and your phenomenal feedback was very much appreciated. Thank you to my family, friends, and classmates that have supported me on this journey for the past three years. Your encouragement, jokes, and support are what helped me keep on trucking. Finally, to my husband, James C. Welch, your endless support and encouragement has been out of this world and I will be forever grateful for all that you did for me and for us during this journey. I am not sure you realize just how important your role was during all of this and all I can say is thank you and I love you. 


\section{Table of Contents}

Background/Statement of the Problem ............................................................... 1

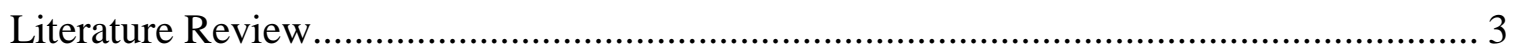

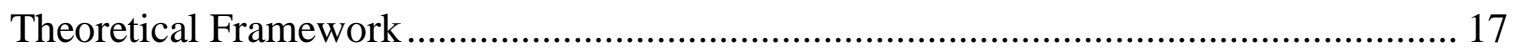

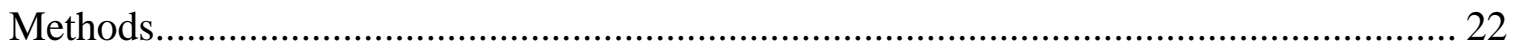

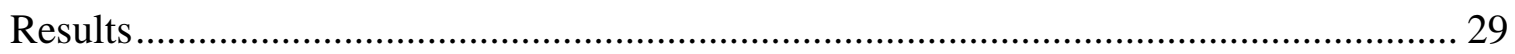

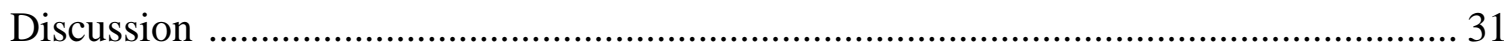

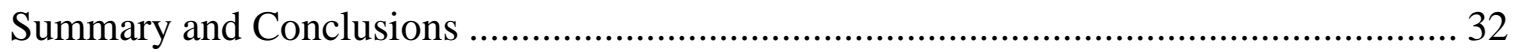

Recommendations and Implications for Advanced Nursing Practice ........................... 35

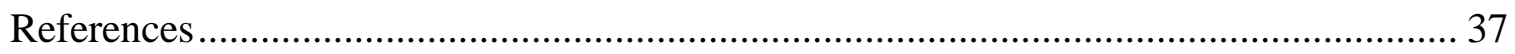

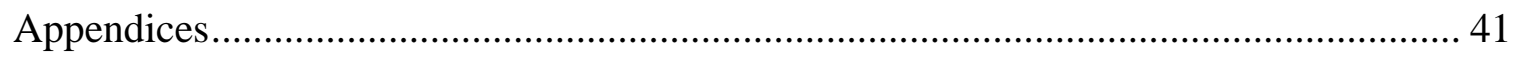




\section{Interprofessional Simulation: Students' Perceptions}

\section{Background/Statement of the Problem}

A variety of professions, including aviation and the military, have utilized simulation in their education and training for practicing and mastering skills (Bradley, 2006). According to the Society for Simulation in Healthcare (SSH), simulation has been recognized as a shift in health care education that can improve skills and patient safety and outcomes (2017). Simulation in the area of healthcare is becoming a significant enough piece of the education and training that even the Institute of Medicine (IOM) has recommended the use of simulation as a method to support nursing in knowledge and skill attainment (IOM, 2003).

In a landmark report by the IOM, "To Err is Human", it was stated that an alarming number of errors occur in the healthcare system (Kohn, Corrigan, \& Donaldson, 2000). The Joint Commission (2016) list both patient safety and improved staff communication as priorities for the 2017 National Patient Safety Goals. The Institute of Medicine (IOM) responded to the error rate by encouraging changes in professional education and recommending interdisciplinary team training. The goal was to improve teamwork and collaboration in the education setting with the expectation that it would flow to the professional setting and result in improved patient outcomes (IOM, 2003). Titzer, Swenty, and Hoehn (2012) demonstrated that simulation is perceived as a useful strategy to teach teamwork among interdisciplinary groups and pointed out that students' perceptions of other health professional roles and priorities was not measured. The measurement of these perceptions served as the basis for this study.

The purpose of this study is to examine undergraduate nursing students, graduate social work students, and advanced practice registered nurse (APRN) students' 
perceptions of one another as healthcare professionals using interdisciplinary simulation. The proposed research question is: Does the use of interprofessional simulation improve the perception of respective roles after simulation.

Next, a review of the relevant literature will be presented. 


\section{Literature Review}

A literature review search was performed utilizing the Cumulative Index to Nursing and Allied Health Literature (CINAHL), PubMed, Medline, and Academic Search Complete. The literature searched from 1999 to present included the keywords: simulation, aviation safety, simulation in healthcare, interprofessional education in healthcare, interprofessional simulation in healthcare and perceptions of interprofessional simulation.

\section{Simulation}

Bradley (2006) defined simulation as a technique of imitating behavior of situation or process by means of suitably analogous situation or apparatus especially for the purpose of study or training. Bradley dates the use of simulation back centuries and points out that the military is largely responsible for the continued use of simulation for practice and training. In addition to the use in military training, aviation has utilized simulation and developed high fidelity simulators to recreate flight. Aviation has also used simulation for improving non-technical skills of teams through crew resource management programs (Bradley, 2006). The nuclear power industry and space industry have utilized simulation for training because system testing and training within the realworld operations would be too costly or dangerous (Bradley, 2006).

Ulrich and Mancini (2014) state that one of the foundations of simulation is based on the unique education strategy that simulation paired with technology helps develop skills, competencies, and clinical judgement. The first training mannequin was developed in 1911 in Rhode Island as "Mrs. Chase" and was used primarily for nursing education (Ulrich \& Mancini, 2014). The technology and advances continued throughout the 
twentieth century to the high-fidelity human patient simulators that are used today and capable of mimicking many functions of the human body (Ulrich \& Mancini, 2014).

Taylor, Dixon-Hardy, and Wright (2014) evaluated the use of simulation in general aviation training and found that general aviation safety would benefit from implementation of regulated simulation training. The study took place in the United Kingdom. The researchers reviewed data from the 1,007 general aviation accidents, which are considered noncommercial, in that country that occurred between January of 2005 and December of 2011. The researchers reviewed the particulars of the pilots including flying experience, age, and type of license (commercial or general) held. The pilots experience was divided into three areas: currency, how much time was done in the past one to three months, type of experience on a particular make and model of aircraft, and total experience. Each accident was entered into one of four categories for qualitative analysis: loss of control, airmanship, technical, or meteorological. The main cause of the accidents stemmed from loss of control, which was often exacerbated by lack of recent flying experience. Taylor et al. found that the licenses of private pilots in the UK state that a maximum of five hours may have been in a flight simulator. The commercial pilots are trained extensively in flight simulators for instrument procedures, emergencies, and flying a simulation of their actual aircraft prior to transitioning to an aircraft. The commercial pilots return biannually to the simulator for practice and competency assessment. The researchers concluded that lack of control was a major issue in the accidents and was perpetuated by lack of pilot experience and currency. Unfortunately, restrictive regulations provide no incentive for training schools to invest in simulators even though the evidence suggests that the simulator will be an invaluable tool for 
reducing accidents related to lack of control as well as improving levels of currency and staying up to date on recent training hours.

\section{Simulation in Healthcare}

According to Jeffries (2005), simulation is a learning activity that can easily

mimic the reality of a patient as well as a traditional clinical environment. She states that nursing educators implement simulation to increase students' clinical diagnostic skills and simulation is essential to the educational experience (Jeffries, 2005). Jeffries (2007) continues by stating that simulation can be used from the most novice of nursing students in the beginning of their education to practice skills and care in a safe environment and then simulation use can progress to high-fidelity experiences where decision making and critical thinking are being learned. The work by Jeffries has provided an evidence based, framework driven approach to designing, implementing, and evaluating the use of simulation in nursing education (Jeffries, 2007).

Jeffries and Rizzolo (2006) performed a national, multi-site, multi-method study project that had four goals in relation to simulation in nursing. The purposes of the longitudinal study were: (a) to develop and test simulation models that nursing faculty could implement to promote student learning, (b) to develop a team of nursing faculty who can use simulation, (c) to contribute to the simulation body of knowledge, and (d) to determine collaboration between profit and nonprofit worlds. The research was done in phases and included multiple sites nationwide as well as randomly controlled participants in different simulation groups. The researchers concluded that the more active the learning experience, the more important feedback is to the learner. The researchers concluded that involvement in a simulation provides the opportunity to apply and 
generate knowledge in a realistic but non-threatening environment. The researchers also said that active involvement and opportunity to apply observational, assessment, and problem-solving skills, followed by a reflective thinking experience, leads to increased self-confidence in students. They stated that feedback received also facilitates learning (Jeffries \& Rizzolo, 2006).

In a study that examined the value of simulation in medical and healthcare education, Okuda, et al. (2009) performed a systematic review and studied one hundred and thirteen articles related to simulation and education. The purpose of the study was to find evidence for the utility of simulation in healthcare education. Simulation in healthcare education was first utilized as early as the 1950s when two anesthesiologists used a mannequin to teach airway and resuscitative skills (Okuda, et al., 2009). The use of simulation led to improvements in medical knowledge, comfort in performance of procedures, retesting improvements in simulated scenarios, increased level of teamwork, and communication. Only a few studies showed direct improvement in clinical outcomes and the authors acknowledged that additional studies should explore if simulation training actually improves patient outcomes (Okuda, et al., 2009).

Like the medical education review, Cant and Cooper (2010) conducted a systematic review of simulation-based learning in nursing education. The review included twelve quantitative studies from January 1999 to January 2009 using primary search terms of simulation and human simulation. The authors found that the reviewed studies reported simulation was a valid teaching tool and learning strategy. The researchers stated that all of the included studies reported statistical improvements in knowledge or skill, critical thinking ability, and/or confidence after the simulation 
education (Cant \& Cooper, 2010). Six of the twelve studies demonstrated additional improvements in increased knowledge, critical thinking ability, and satisfaction compared to control groups. The researchers concluded that medium or high fidelity simulation with mannequins, adhering to best practice guidelines, is an effective teaching and learning method and recommended further exploration in effect of team size on learning and developing a universal method of outcome measurement.

In a large-scale, randomized, controlled, longitudinal study, the National Council of State Boards (NCSBN) provided evidence that simulation can be a replacement strategy for traditional clinical hours in addition to being an effective teaching tool in nursing education (Hayden, Smiley, Alexander, Kardong-Edgren, \& Jeffries, 2014). Many nursing programs nationwide are seeing more challenges in obtaining high-quality clinical experiences due to a variety of reasons and simulation was found to be a comparable alternative to traditional clinical experiences. The NCSBN study is considered the landmark, multi-site study that looked at the use of simulation in prelicensure nursing programs nationwide. The study was done in three in phases. The first phase examined how simulation was being utilized in institutions across the country. The second phase randomized incoming nursing students from ten prelicensure programs and put them into three groups: (a) a control group of students who had traditional clinical experiences, (b) the $25 \%$ group that had $25 \%$ of their traditional hours replaced by simulation, and (c) the $50 \%$ group where students had $50 \%$ of their traditional clinical hours replaced by simulation. The third phase was the longitudinal aspect that then followed the participants into the first six months of their nursing practice postgraduation. A total of 666 students completed the study requirements at the time of 
graduation. The researcher noted no statistically significant differences in clinical competency as assessed by clinical preceptors and instructors, in comprehensive nursing knowledge assessments and in board exam passing rates among the three study groups (Hayden et al., 2014). No differences in clinical competency or readiness for practice as assessed by manager ratings were noted up to the studied six months in clinical practice. (Hayden et al., 2014). The results from the study provided evidence to the boards of nursing nationwide that permission could be granted to use simulation as a replacement for some clinical hours to help reduce some of the challenges faced by nursing programs nationwide when it comes to obtaining clinical placements (Hayden et al., 2014). Limitations to the study included: (a) lack of randomization of the sites; (b) sites chosen were those that had an interest in simulation and were equipped with adequate simulation equipment; (c) managers and preceptors that were not blinded to the group assignments, which could have led to biases; and (d) students in the third phase that were required to take initiative regarding post-testing evaluation. Despite these mentioned limitations, the researchers conclude that the study provides important information for educators in healthcare that are determining the best methods in teaching students and the future nursing education (Hayden et al., 2014).

\section{Interprofessional Simulation Education in Healthcare}

Titzer, Swenty, and Hoehn (2012) developed a study to describe an interprofessional simulation exercise that utilized students from four professional programs. The researchers assessed three different learning outcomes: (a) students' perceptions of simulation as an interprofessional teaching strategy with a focus on collaboration and problem solving, (b) students' perceptions of the importance of 
simulation as a teaching strategy for collaboration and problem solving, and (c) the students' perception of other disciplines within healthcare (Titzer, Swenty, \& Hoehn, 2012). The simulation included 79 baccalaureate nursing students, 15 baccalaureate radiologic technology students, 27 baccalaureate occupational therapy students, and 10 associate respiratory therapy students. The goal was to improve collaboration and problem solving amongst these disciplines. The simulation was followed by a debriefing session that allowed the team to discuss their care, prioritization, and coordination. After debriefing, the students evaluated the simulation and their perceptions of the use of simulation as an interprofessional teaching strategy by completing the Educational Practices Simulation Scale (EPSS), a quantitative tool, and the Healthcare Provider Survey (HPPS), a scale developed by three members of the nursing faculty, for qualitative data. The EPSS was used to measure the student's perception of the use and its importance of simulation as an interprofessional teaching tool for teaching collaboration and problem solving. The HPPS measured students' perception of the simulation experience by evaluating the perceptions of each discipline's role and priorities during the simulation. The simulation experience counted towards clinical hours, therefore was mandatory although not graded. All participants completed the study. The researchers found that the use of interprofessional education simulation fostered an effective learning environment and the students reported a better understanding of the roles of the other disciplines with a mean of 4.43 on the 5-point Likert scale. The researchers also noted that the multidisciplinary simulation increased communication among health care providers and concluded that the simulation was an effective method for teaching collaboration with a mean score of 4.40 on the Likert scale. 
A limitation of the study was the lack of a pre-test to determine students' perceptions of the other healthcare professional roles. It was unknown what prior experiences and perceptions existed before the simulation. Additionally, mandatory participation could have had an impact on the results if the participants felt that the researchers were looking for particular answer or if they felt their responses would be somehow graded or linked to them.

Scherer, Myers, O’Connor, and Haskins (2013) conducted a study that examined the effect of interprofessional simulation. The study consisted of a convenience sample of 85 nursing students and 23 medical students in a quasi-experimental pre-test, posttest design using an experimental group and a control group. The interprofessional group served as the experimental group and consisted of 48 nursing students and 23 medical students. The control group was strictly an intraprofessional group of 37 nursing students that participated in the same simulation with no medical students present. The interprofessional and intraprofessional groups were compared in terms of knowledge, confidence, and attitudes towards interprofessional learning, teamwork, and collaboration by completing five paper and pencil surveys. The researchers discovered that the students in the interprofessional group had a 46 percent higher score on knowledge, teamwork, collaboration, professional identity, and roles and responsibility compared to the students that participated in the control group. The authors concluded the use of interprofessional education (IPE) in simulation can be an effective teaching tool to improve the attitudes toward learning in cooperation with students from other disciplines as well as the importance of teamwork. The limitations of the study included the use of a 
convenience sample, small sample size, and unequal group sizes due to scheduling conflicts.

Similarly, Alinier, et al. (2014) studied the knowledge and perceptions of participants of interprofessional simulation and the roles and skills of other healthcare professionals by performing a quantitative study on 237 undergraduate students in nursing, radiography, radiotherapy, physiotherapy, midwifery, paramedic science, social work and pharmacy. The students were in semi-random selected experimental or control groups based on their arrival to the simulation center and their profession to ensure equal representation in both groups. The group assigned determined whether they completed the knowledge questionnaire before or after the simulation exercise. The control group were given questionnaires one and two before the simulation exercises, whereas the experimental group completed questionnaire one prior to the simulation and questionnaire two following the simulation. The first questionnaire, Q1, was used to collect demographic information about the participants. It also gathered data about their previous experiences in scenario based simulation. This scale used a 5-point Likert scale. The second questionnaire, Q2, was labeled as the discipline-specific knowledge questionnaire and consisted of five statements to determine students' views of multiprofessional working and IPE using the same 5-point Likert scale. Q2 also had 40 true-false statements as an easy and objective way to score. Both groups then completed a post simulation experience evaluation questionnaire, Q3, which was used to encourage reflection and, along with Q1, is a part of the generic simulation questionnaire used by that simulation center for most sessions. Q2 was newly developed for the sake of the research study. The authors concluded that the experimental group, those that completed 
Q2 after the IPE exercise, had a higher appreciation for and knowledge about the professionals from different disciplines. The study showed that through a limited exposure to a simulation experience, the perceptions from students were positive in regard to different aspects of multidisciplinary learning and working. The experimental group was determined to feel more confident working within a multidisciplinary team with statistically significant $p$ value of 0.03 . A limitation of the study was the researchers utilized undergraduate participants from cohorts across three years from five different disciplines at one university, rather than studying groups in a one-time setting. Another limitation was use of a convenience sample and the limited prior exposure to interprofessional simulation. The authors also identified that the second questionnaire used may have had some sensitivity and reliability issues related to the fact that it did not have a lot of questions about each profession.

Bolesta and Chmil (2014) studied interprofessional education by incorporating pharmacy students as participants in an interprofessional simulation. The investigators designed an interprofessional education scenario that utilized both pharmacy and nursing students in collaborative practice to diagnose and treat an ill patient. The 69 pharmacy students and 51 nursing students were surveyed with 64 students consenting to participation and completing both surveys. The students completed both a pre-test and posttest survey to assess their attitudes towards and readiness to participate in an interprofessional education by completing the Readiness for Interprofessional Learning Scale (RIPLS). The findings in the study also support the use of interprofessional education. Students' attitudes toward interprofessional education improved and the 
students reported feeling prepared not only for future interprofessional education experiences, but with interprofessional communication skills as well.

\section{Perceptions of Interprofessional Simulation}

Baker, et al. (2008) focused on the learner and teacher reactions and perceptions of interprofessional education simulation in a mixed methods pilot study research project. Two pilot modules were studied. The first module was a cardiac resuscitation that was two hours in length and included fourth year nursing students and third and fourth year medical students. The second pilot was a shared competency module and was used to teach intravenous access to third year nursing students and second year medical students. Participants included: 101 nursing students, 42 medical students, and 70 junior medical students who completed the study in the first academic year; an additional 20 medical students, 7 junior medical students, and 45 nursing students completing the first pilot study in the fall of the second year. The second pilot study had 71 nursing students and 75 medical students during the winter term. The researchers used both a Likert scale with the 18-question Interdisciplinary Education Perception Scale as well as open ended questions that were collated and categorized for data analysis. The researchers reviewed positive results for the attitudinal scores and written comments of the learners and found little variation in responses between disciplines (Baker, et al., 2008). The participants perceived that they had a better understanding of team roles as a result of the simulation sessions. The researchers also found that there was a high degree of awareness of the interdependence between their profession and other healthcare professions (Baker, et al., 2008). 
Liaw, Siau, Zhou, and Lau (2014) conducted a pretest-posttest study that examined the effect of an interprofessional simulation on perceptions of each other's professions. The study was a prospective, quasi-experimental pretest and post-test design at a university in Singapore. The participants were 102 medical and nursing students who attended the interprofessional simulation-based communication education program. The study demonstrated that by bringing together both medical and nursing students via interprofessional simulation, their perceived views of each other's profession can improve. The findings were strongly associated with improved attitudes towards nursephysician collaboration. The investigators concluded that the introduction of this collaborative learning experience, even at the pre-licensure level, has great potential for preparing future healthcare teams to promote collaborative patient-centered care (Liaw, et al., 2014).

\section{Interdisciplinary Education Perception Scale (IEPS)}

The Interdisciplinary Education Perception Scale (IEPS) is an 18-question Likert scale questionnaire that measures the effect of interprofessional education experiences on students (Appendix A). The tool has four subscales: competency and autonomy, perceived need for cooperation and perception of actual cooperation and understanding others' roles (Luecht, Madsen, Taugher, \& Petterson, 1990). The tool was designed to measure the professional perceptions of students exposed to interdisciplinary settings, relative to their own professional and other allied health disciplines (Luecht, Madsen, Taugher, \& Petterson, 1990).

The scale was later remolded by McFadyen, Maclaren, and Webster with the four subscales being modified to three subscales of: competency and need for autonomy, 
perceived need for cooperation, and perception of actual cooperation (2007). The problem with the modified instrument was that the psychometric properties as well as the content validity were potentially affected (Leitch, 2014). Leitch performed a research study that tested both existing sub-scale structures of the IEPS in a population of graduate students in health care to determine which was a better fit for that population, and also to explore the content of the IEPS to gain a better understanding of the constructs that are measurable by this scale (Leitch, 2014, p. 52). The study was conducted with students in a health professional program at a public university in the Mid-Atlantic region. Of the 4,771 students that were emailed the study, 490 responded for a response rate of $10.3 \%$. Of the returned surveys. Only 227 were fully completed leaving a useable response rate of $4.8 \%$. The graduate student breakdown was 47 nursing students, 47 medical students, 53 pharmacy students, 19 dental students, and 63 social work students. Two students were listed as dual program members. The findings from this study that compared the original IEPS scale with the modified one found that when studying only graduate students, the modified scale may be a better option. The diversity of the group of professions likely created more variability in responses that were not supported by the four factor subscales (Leitch, 2013). The original population that was studied with the IEPS included students from both the undergraduate and graduate level, as well as administrators. Leitch also mentions that the findings from the modified, three subscale measurement had reported low reliability and that the change and loss of the original items may impact the original interpretability of the instrument (Leitch, 2014). 


\section{Gaps in Literature}

As interprofessional education simulations continue to expand in healthcare and nursing education, research exploring the efficacy of these programs needs to expand as well. Scherer, et al. (2013) concluded that more research is needed to evaluate the longterm and short-term effects of simulation in education in both academia and the clinical setting. Bolesta and Chmil (2014) also discussed the need for more evaluations to measure the effects of these collaborative education practices. Some of the major barriers to interprofessional education simulation are the cost of development, coordination, and implementation of these programs. To best replicate a clinical situation, all members of the healthcare team should be present, but that is not always possible. Not all universities offer programs for every area of healthcare, making some important interprofessional relationships difficult to simulate. Most studies of interprofessional education are limited in the disciplines participating. Involving more disciplines will only enhance the interprofessional education experience and move the education from the silo of individual professions. In this researcher's review of the literature, the inclusion of the APRN and graduate social work students in interprofessional simulation is lacking. The purpose of this research is to include these disciplines, along with undergraduate nursing students to evaluate the effect of interprofessional simulation on students' perceptions of others' roles within the healthcare team using the original IEPS instrument. The literature review findings led this researcher to utilize the original IEPS scare over the modified version. Next, the theoretical framework will be discussed. 


\section{Theoretical Frameworks}

The Kolb Experiential Learning Theory (ELT) and Jeffries Simulation framework are to guide this research project. The Kolb ELT describes the learning process as a cycle: includes real life experiences, reflective observation, abstract conceptualization, and active experimentation. The theory also recognizes the importance of individual learning styles. The National League of Nursing Jeffries Simulation Framework (NLN/Jeffries Simulation Framework) was developed by the National League of Nursing as a consistent model to serve as guide for simulation development and implementation. The framework consists of five conceptual components that not only takes into consideration the educators and participants, but also the relationships between the simulation design, outcomes, and knowledge gained. The NLN/Jeffries Simulation Framework concepts support Kolb's ELT with interprofessional education because they incorporate how the participants learn and how collaboration matters and impacts the design of a simulation.

\section{Kolb's Experiential Learning Theory}

A common learning theory used as a framework in simulation is the Kolb's ELT

(Poore, Cullen, \& Schaar, 2104). Ulrich and Mancini (2014) state that the procurement of knowledge comes from the ability to transfer theoretical knowledge and apply it in a practical setting. According to Kolb's ELT theory, learning will be greatest with participation and reflection in a skill that requires problem solving and decision-making as a result. The student will actively gain knowledge through experience. Kolb's theory describes the learning process as a four-step cycle that includes concrete experiences, reflective observation, abstract conceptualization, and active experimentation (Kolb, 1984). Kolb states that in the early stages of development, growth in these four cycles can occur independently, however at the highest stages of development focus on the 
dimensions need to be integrated: "Development in one mode precipitates the development of others" (Kolb, 1984, p. 140). He describes the learning process as a continuous one grounded in experience that has important educational implications (Kolb, 1984). Kolb goes on to say that for educational purposes, all learning is relearning. Everyone enters every learning situation a wide variety of information regarding the topic at hand (Kolb, 1984).

In addition to describing learning as a four-step cycle, Kolb recognizes the importance of individual learning styles and states that individuals have preferences for obtaining knowledge. Kolb describes learners as: diverging learners, assimilating learners, converging learners, or accommodating learners (Kolb, 1984). The diverging learner learns best through concrete experience and reflective observation. Diverging learners possess imaginative abilities and perform best in situations where they need to generate ideas or brainstorm. The converging learner is the opposite of the diverging learner and learns best through abstract conceptualization and active experimentation. Converging learners prefer technical tasks and are considered problem solvers and decision makers. Converging learners seem to do best in situations with one single correct answer or solution to the problem. The assimilating learners learn best through reflective observation and abstract conceptualization. Assimilating learners are most interested in abstract concepts, can transfer that information in a logical manner with inductive reasoning, and are less focused on people and more concerned with ideas and abstract concepts. The accommodating learner is the opposite of the assimilator and prefers concrete experience and active experimentation and prefers a hands-on approach to learning. Accommodating learners do well with carrying out tasks and are best suited 
for situations where they must adapt to changing circumstances and can discard theory (Kolb, 1984). These learning styles, paired with experience, determine the extent to which the person emphasizes the previously described four modes of the learning experience: concrete experience, reflective observation, abstract conceptualization, and active experimentation (Kolb, 1984). Kolb's ELT also provides six propositions to the theory that serve as the basis for how knowledge is generated. The six steps include: (a) learning is a process, (b) all learning is relearning, (c) learning is a dialectic process, (d) learning is holistic and integrative, (e) learning results from interactions between person and environment, and (d) learning is the process of creating knowledge (Kolb, 1984). The Kolb ELT is a combination of how individual learning styles and the six propositions come together in a continuing cycle to generate knowledge through the transformation of experience.

Poore, Cullen, and Schaar (2014) discuss how using Kolb's theory as the basis for IPE simulation not only can be an excellent framework for simulation learning, but also a strategy to master effective communication and collaboration. The authors discussed how the congruence between Kolb's theory and the way learners gain knowledge fits well with simulation education that incorporates many healthcare team members. Kolb's theory is based on a cyclical process of learning, which is important when there are members of the healthcare team with different experiences and learning styles. One or all four of Kolb's learning styles may be utilized at the various stages of the learning process. Poore, Cullen, and Schaar (2014) state that IPE and the improvement of collaboration and communication among the members of the healthcare team can also be viewed as a cyclical process. Communication and teamwork are shaped through 
experience and exposure. Those experiences change future thoughts and behaviors leading to improved communication and teamwork. Kolb's (ELT) is also a testable theory and is used in other professions, making it more appealing to IPE and simulation.

\section{Jeffries Simulation Framework}

Accompanying the use of a well-known learning theory, simulation education also requires a specific simulation framework to ensure that the design and operation of the simulation is reliable and effective. One of the most highly regarded theories used in simulation is the NLN/Jeffries Simulation Framework that was developed by the National League of Nursing as a consistent model to serve as a guide for simulation development and implementation (Jeffries, 2012). This framework, comprised of five conceptual components, not only considers the educators and participants, but also the relationships between simulation design, outcomes, and knowledge gained. The NLN/Jeffries Simulation consists of five components: the facilitator, the participant, the educational practices that need to be integrated, the design of the simulation, and the expected outcomes. A successful design and implementation needs to take into account all of these components for a positive overall experience. In addition to a strong simulation framework serving as the foundation of implementation, Jeffries points out that a variety of educational practices need to be well thought-out when designing a simulation. Active learning, feedback, diverse learning styles, and collaboration are all components of educational practices that Jeffries identified as important facets of the simulation template (Jeffries, 2012).

Jeffries (2012) states that when simulation is conducted for research without an organizing framework, the variables cannot be studied in a consistent manner and the 
effectiveness of the simulation would be difficult to define. Jeffries continues by stating that without a proper theoretical framework, the research is not organized or done in a systematic manner, and the influencing factors become vague. It is imperative that a conceptual framework is presented to guide the relevant variables and their relationships. This practice of the NLN/Jeffries Simulation Framework with Kolb's ELT for IPE because the ELT incorporates how the participants learn and how collaboration should be considered when designing a simulation to improve student learning, performance, and satisfaction.

For this research project, the use of Kolb's ELT and the NLN/Jeffries Simulation Framework together provide the needed learning theory and guidelines to conduct the research on the perceptions that the simulation participants have of each other's respective disciplines. 


\section{Methods}

\section{Purpose}

The purpose of this study was to examine undergraduate nursing students, graduate social work students, and APRN students' perceptions of one another as healthcare professionals using interprofessional simulation. The research question was: Does the use of interprofessional simulation improve the perception of respective roles after simulation.

\section{Design}

This research study was a quantitative descriptive study using a pre-test, intervention, post-test design. The participants were asked to complete the IEPS questionnaire, an eighteen-question survey with a 6-point Likert scale. After completion of the survey, the participants took part in four previously utilized interprofessional simulations scenarios with debriefing sessions following each scenario. At the end of the day the participants then complete the same IEPS questionnaire. The study took place over six scheduled IPE simulation days and included different participants each time.

\section{Sample}

A nonprobability convenience sample of senior level undergraduate nursing students, graduate level social work students, and graduate level APRN students that include acute care nurse practitioner students and clinical nurse specialist students from Rhode Island College were included in the study. All participants had at least one clinical rotation. The undergraduate nursing students were senior level students who had participated in simulation in the past and had been out in the clinical settings. There were 96 students enrolled in the course and were participants in the IPE simulation. There 
were 13 Acute Care Nurse Practitioner students and five Clinical Nurse Specialist students enrolled in Adult Health II and participants in the IPE. Forty-One Social Work students were involved in the IPE simulations. All the students partaking in the IPE simulations were eligible for the research study. There were no exclusion criteria of any of the mentioned students for this study. The goal was a sample size that was at least onethird of the enrolled students for these courses. A total of 155 students were eligible for participation in the study. One hundred and nine students participated for return percentage of 70 percent.

Site

The surveys were administered at Rhode Island College, Fogarty Life Science in the Clinical Simulation Laboratory in Room 163 in the Fall Semester of 2016. Rhode Island College is a state college public, comprehensive college located in the capital city of Providence, Rhode Island with a total undergraduate and graduate enrollment of just under 9,000 students. The Rhode Island School of Nursing has both undergraduate and graduate level programs with over 600 students.

The Simulation Center and Nursing Resource Laboratory is a nationally accredited program by the Society for Simulation in Healthcare. Simulation has been a part of the curriculum at Rhode Island College for over ten years and the interprofessional education simulations have been utilized within the college for seven years.

\section{Procedures}

The faculty and instructors for the courses in the Bachelors of Science in Nursing (BSN) and Masters of Science in Nursing (MSN) programs within the School of Nursing and the Masters of Social Work (MSW) were contacted by email and granted permission 
to study students in the four IPE simulation classes. Permission was also obtained from the Simulation Educator and from the Dean of the School of Nursing. After obtaining permission, the proposal was submitted to and approved by to Rhode Island College Institutional Review Board (IRB).

The schedule for each day can be found in the Interprofessional Simulation Daily Schedule (Appendix B) and provides a detailed timeline for the four simulations. The daily schedule was replicated six times during the semester with different participants. Time for study introduction and pretest, posttest data collection was allotted.

Participation in the IPE simulation day is a standard component of the curriculum for all disciplines involved: undergraduate nursing students, graduate level social work students, and graduate level acute care nurse practitioner students, and clinical nurse specialist students. The orientation to the Rhode Island College Simulation Center was done by the Simulation Coordinator/Educator and by the faculty of each discipline. An informational letter (Appendix C) was provided along with instruction prior to handing out the questionnaire. The researcher or a colleague of the researcher was available to talk about the study and was on hand to answer questions about the research study. The students' participation in the study was voluntary and participation in the pretest-posttest was considered implied consent. The students were assured that their decision to participate in the study had no bearing on their grade or on their active roles within the simulation. The student researcher had no knowledge of who agreed or declined study participation.

Participants were asked to complete the IEPS questionnaire, an eighteen-question survey with a 6-point Likert scale. No identifiable demographic data was requested. 
Participants wrote their mother's birthdate on both the pretest and posttest to compare individual as well as aggregate responses. The pretest and posttest questionnaires were colored differently to differentiate between the two tests.

The researcher or assistant distributed the pretest prior to the first of four simulations (Appendix A) and then left the room. All the students were given the surveys, regardless of participation in the study and were asked to put their surveys in the manila envelope. Providing all of the students the survey avoided knowledge of who completed the survey. The envelope was then sealed and collected by the researcher or assistant to avoid faculty involvement and perceived coercion.

Students were divided into groups of 8-10 participants. Each group contained a nurse practitioner student, a clinical nurse specialist student, a social work student, as well as undergraduate nursing students. The groups alternated between simulation exercises, and debriefing sessions for all scheduled simulations. At the end of the simulation day, the researcher or assistant administered the posttest. The students used the same identifier, mother's birthdate, in order for the researcher to compare pre-and post-test scores. All students were reminded that participation is voluntary and responses are confidential. The students placed the completed posttest surveys in a manila envelope, which was sealed and collected by researcher or assistant at the end of the day. The surveys were stored in a locked filing cabinet and will be stored for minimum of three years following the conclusion of the research study, after which they will be destroyed.

\section{Measurement}

The IEPS is an 18-question Likert scale questionnaire that measures the effect of interprofessional education experiences on students (Appendix A). It is a commonly 
used questionnaire where Cronbach's alpha and internal consistency have been reported. The researcher examined the mode, median, mean, range, and standard deviation. The data allows for understanding of the most common findings as well as the averages of the groups, but also includes a measure of variability to determine how the scores were clustered or deviated from the average in distribution.

\section{Timeframe}

Permission from the IRB was obtained in October of 2016. The data collection took place on the previously scheduled Interprofessional Simulation days of November 1, 3, 10, 22, 29, and December 1, 2016. These days had been coordinated amongst the participating departments prior to the beginning of the 2016-2017 academic year. After data collection, a statistical analysis with Statistical Package for the Social Sciences (SPSS) software after the semester was performed. The study was presented as a poster for the Rhode Island School of Nursing Major Projections Presentation on May 2, 2017.

\section{Organizational/Systems Factors}

Exploration of Resources. This use of RICSON accredited high fidelity Simulation Center and Nursing Resource Laboratory was a resource benefit to this study. The newly built facility provides a conducive, learning environment. The four IPE simulations involving undergraduate nurses, social work, nurse practitioner and clinical nurse specialist students have been established within these disciplines for a number of years and the IPE simulations were an important part of the disciplines' curriculum.

Enabling Factors. The enabling factors for this research study included support of RISON leadership and simulation coordinator/educator. The support from the Dean of 
the RISON as well as the support from the professors from the school of Social Work was required for this research project as well.

Potential Barriers and Biases. The potential barriers to this project included the willingness of participants to complete the pre/post survey as well as the possible time constraints related to the already busy IPE schedule listed in Appendix B. A potential bias was that APRN participants were current classmates of the researcher and may have felt pressured to participate.

\section{Desired Outcomes}

The desired outcome of this simulation study was to determine if participating in IPE simulation changed the perceptions of students.

\section{Outcome Measurement}

The outcomes were measured by the IEPS, an 18 question Likert scale questionnaire, that measures the effect of interprofessional education experiences on students. Cronbach's alpha and internal consistency have been reported. Luecht, et al. (1990) reported that the Cronbach's alpha of all items measured have a coefficient 0.87 , indicating high overall internal consistency. This tool has been discussed at length throughout this proposal.

\section{Identification of Ethical Concerns}

This research project required RIC IRB approval and it fell under exempt level of review. The subjects could freely consent and there were no risks to the subjects/participants. The subjects were not identified. The participants of the study were current students and fell under the category of a vulnerable population. No diversity 
issues were noted with this study. No identifying information was collected. The researcher asked for mother's date of birth only to compare pre-and post-test responses.

The researcher was a Graduate Assistant in the Simulation Center. To prevent any influence on the outcomes of the study or conflict of interest, the Simulation Coordinator/Educator and the participating Rhode Island School of Nursing (RICSON) faculty assisted with data collection procedures. The Simulation Coordinator/Educator or colleague of the researcher provided an overview of the purpose of the study and distributed the RIC IRB approval letter. 


\section{Results}

The data collected was analyzed with SPSS and calculated with descriptive statistics to compare the pretest and posttest results and the Wilcoxon signed rank test was used for an analysis of variance and significant difference for each question. The Wilcoxon test was chosen since the Likert scale results were not normally distributed. Each question was run with an assumed level of significance set at 0.05 , meaning that there would be a less than five percent chance that the change in values between pre-and posttest surveys would be due to random chance.

A total of 155 students participated in the interprofessional simulations which resulted in 109 completed research surveys, giving a response rate of 70 percent. Some completed surveys were unusable due to lack of matching pre-or post-survey. There were 13 pretests and 10 posttests did not have a matching identifier or an identifier at all and were not entered into the statistical formulas.

Table 1 (Appendix D) demonstrates the results of the surveys. In 17 of the 18 questions a statistical difference in the mean scores between the pretest and posttest surveys was found. Fifteen of the 18 questions had measurements of 0.000 , showing very significant differences between the pre-test and post-test surveys. Question seven and question eleven had statistical measurements of 0.003 and 0.009 , respectively. The results were still found to be significant but not at the same level as the other questions on the tests. Table 1 (Appendix D) contains the responses to IEPS with descriptive statistics including the mean, median, and mode as well as the Wilcoxon p value for each question. On question six, which asked "Individuals in my profession need to cooperate with other professions", the significance was greater than 0.05 , with a measurement of 0.179 , 
indicating no difference in findings between the pre-test and post-test for this particular question. 


\section{Discussion}

The purpose of this study is to examine undergraduate nursing students, graduate social work students, and APRN students' perceptions of one another as healthcare professionals using interdisciplinary simulation. All of the questions showed improvement between pre-and posttests. In 17 of the 18 questions, statistically significant results demonstrate that the simulations were beneficial to the participants. A number of questions had improvements in all three measures of descriptive statistics of mean, median, and mode between the pre-and posttests. All of but one of the questions showed a significant improvement in perception from pretest to post test results. The question that did not demonstrate a significant difference asked if individuals in my profession need to cooperate with other professions. One reason for the lack of significant difference may be attributed to the high mean of 5.71 on the pre-test. The majority of participants strongly agreed with the statement prior to the simulation as the median and mode were both at the highest level out of six. There was improvement noted on the post test, but only to 5.83 . Both pre-and post-tests had similar median and mode findings of on a six-point scale. It can be concluded that exposure to interdisciplinary simulation leads to increased perceptions of respective disciplines. 


\section{Summary and Conclusions}

An alarming number of errors occur in the healthcare system (Kohn, Corrigan, \& Donaldson, 2000). The IOM responded to the error rate by encouraging changes in professional education and recommending interdisciplinary team training. Research shows that a variety of professions, including aviation and the military, have utilized simulation in their education and training for practicing and mastering skills. In addition to mastering skills, simulation can assist with respect and appreciation of other professional roles on the healthcare team. Teamwork has been found to be an imperative component of decreasing errors and providing safe and effective healthcare. The purpose of this study was to examine undergraduate nursing students, graduate social work students, and APRN students' perceptions of one another as healthcare professionals and determine if the use of interdisciplinary simulation have an impact on those perceptions. This research study was a quantitative descriptive study using a pre-test, intervention, post-test design with a nonprobability, convenience sample of students enrolled at a public university in Providence, Rhode Island. The participants were asked to complete the IEPS questionnaire, an eighteen-question survey with a 6-point Likert scale. The participants then took part in four interprofessional simulations scenarios with debriefing sessions following each scenario. These simulation scenarios with debriefing sessions were a part of the curriculum for each of the disciplines. The same IEPS was completed at the end of the day. 109 participants from the mentioned disciplines participated in the study. The IEPS measures the effect of interprofessional education experiences on students and statistically significant higher scores were found on the posttest questionnaires in 17 of 18 questions. The study supports the use of interprofessional simulation in higher education and provides students not only with an opportunity to 
work with various members of the healthcare team, but also provides a proven benefit related to perceptions of other disciplines. The study demonstrates the use of interdisciplinary simulation improves professional perceptions of their own professions as well as other allied health disciplines. Participants gained knowledge regarding the other professional participants who were involved in the scenario and if one were to project these findings in the educational setting to clinical practice, actual changes in behavior may occur such as improved communication and respect for the roles of the other caregivers. The statistically significant improvements could have a clinically relevant impact on patient safety and improved patient outcomes.

While statistically significant findings were found, the study did have some limitations. The study used a convenience sample of students already enrolled in the studied programs. The simulations were a part of the curriculum and the disciplines have already been established for the interdisciplinary work done at the college prior to the research being done. Another limitation to the study was not asking identifying information regarding which discipline the participants were from and comparing those answers. All of the surveys were done anonymously with no identifying markers were asked, which included their respective discipline. A recommendation for future research would be to separate the findings by discipline to compare and measure each discipline separately and as a whole. Another limitation includes the lack of control group in this study. No group was required to fill out the surveys without the intervention of the simulations. The use of the survey again could have affected the results. Additionally, the researcher is a student in the graduate program studied and also a graduate assistant worker in the simulation laboratory where the simulations took place. The participants 
could have unintentionally felt pressure to participant in the research or to answer in a particular manor. 


\section{Recommendations and Implications for Advanced Nursing Practice}

Errors continue to occur within the healthcare system and continue to harm patients at an alarming rate. The IOM responded to the error rate by encouraging changes in professional education and recommending interdisciplinary team training. The goal was to improve teamwork and collaboration in the education setting with the expectation that it would flow to the professional setting and result in improved patient outcomes. The study examined perceptions of how disciplines view themselves and other members of the healthcare team and the effect than interprofessional educational simulation experience had on those perceptions. The study showed significant improvements on interdisciplinary perceptions and is valuable in building teamwork and providing exposure to other disciplines to replicate clinical situations. A recommendation to educators and future researchers is to include other members of healthcare team. Involving more disciplines will only enhance the interprofessional education experience and move the education from the silo of individual professions to mimic the real clinical situation. Much of the research has been limited to physicians and nurses. Diversification to involve all members of the healthcare team including the interpreter, spiritual care members, rehabilitation specialists, and administrative or support staff is important. These are members of the team that are often forgotten about and underutilized in interdisciplinary simulation.

The findings noted in the study showed increases in participant knowledge and indicates that the use of simulation is beneficial in the curriculum for the studied disciplines. The use of interdisciplinary simulation in higher education has a benefit to the perceptions of the roles of the many members of the healthcare team. In a time when access to clinical settings is limited and patient safety and improved patient outcomes 
continue to be priorities the Advance Practice RN should look at utilizing interdisciplinary simulation to facilitate teamwork and appreciation for the other roles within the busy healthcare system. The Joint Commission (2016) list both patient safety and improved staff communication as priorities for the 2017 National Patient Safety Goals. Nursing educators, as well as educators in other areas of the healthcare system, can use the information as curriculum is built and improve learning activities and experiences for students. It is imperative to escape educational silos in order to enhance communication and collaboration amongst the entire healthcare team. Interdisciplinary simulation offers both a foundation and experience for learning how to improve teamwork and communication.

The use of interdisciplinary simulation training should not stop at graduation. Training is beneficial in any healthcare setting and allows for all members of a healthcare team the opportunity to practice and master skills with actual coworkers. Interdisciplinary simulation in the clinical context provides an opportunity for actual caregivers to improve their teamwork and collaboration. The APRN utilizes healthcare technologies with high fidelity simulation mannequins to replicate high stakes situations that are faced on a consistent basis to lessen the chance of error. 


\section{References}

Alinier, G., Harwood, C., Harwood, P., Montague, S., Huish, E., Ruparelia, K., \& Antuofermo, M. (2014). Immersive clinical simulation in undergraduate health care interprofessional education: Knowledge and perceptions. Clinical Simulation in Nursing, 10(4), e205-e216. http://dx.doi/org/10.1016/j.ecns.2013.12.006.

Baker, C., Pulling, C., McGraw, R., Dagnone, J.D., Hopkins-Rosseel, D., \& Medves, J. (2008). Simulation in interprofessional education for patient-centered collaborative care. Journal of Advanced Nursing, 64(4), 372-379. http://dx.doi/org/10.1111/j.1365-2648.2008.04798.x

Bolesta, S. \& Chmil, J. (2014). Interprofessional education among student health professionals using human patient simulation. American Journal of Pharmaceutical Education 78(5): Article 94. Retrieved from http://www.ncbi.nlm.nih.gov/pmc/articles/PMC4064494/

Bradley, P. (2006). The history of simulation in medical education and future directions. Medical Education, 40, 254-262. http://dx.doi.org/10.1111/j.13652929.2006.02394.x

Cant, R. P., \& Cooper, S. J. (2010). Simulation-based learning in nurse education: A systematic review. Journal of Advanced Nursing, 66(1), 3-15. http://dx.doi.org/ $10.1111 / \mathrm{j} .1365 .2648 .2009 .05240 . x$

Hayden, J., Smiley, R., Alexander, M., Kardong-Edgren, S., \& Jeffries, P. (2014). The NCSBN national simulation study: A longitudinal, randomized, controlled study replacing clinical hours in prelicensure nursing education. Journal of Nursing Regulation, 5(2), 2-64. 
Institute of Medicine. (2003). Health professions education: A bridge to quality. Retrieved from http://www.nap.edu/read/10681/chapter/1

Jefferies, P.R (2005). A framework for designing, implementing, and evaluating simulations used as teaching strategies in nursing. Nursing Education Perspectives, 26, 96-103.

Jeffries, P. R. (2007). Simulation in nursing education: From conceptualization to evaluation. New York, NY: National League for Nursing

Jeffries, P. R. (2012). Simulation in nursing education from conceptualization to evaluation ( $2^{\text {nd }}$ ed). New York: NLN Press.

Jefferies, P.R., \& Rizzolo, M.A. (2006). Designing and implementing models for the innovative use of simulation to teach nursing care of ill adults and children: A national, multi-site, multi-method study. New York: National League for Nursing. Retrieved from http://www.nln.org/docs/default-source/professionaldevelopment-programs/read-the-nln-laerdal-project-summary-report-pdf

Kohn, L. T., Corrigan, J., \& Donaldson, M. S. (2000). To err is human: Building a safer health system. Washington, D.C: National Academy Press.

Kolb, D. (1984). Experiential learning. Englewood Cliffs, NJ: Prentice-Hall, Inc.

Liaw, S. Y., Siau, C., Zhou, W. T., \& Lau, T. C. (2014). Interprofessional simulation-based education program: A promising approach for changing stereotypes and improving attitudes toward nurse-physician collaboration. Applied Nursing Research, 27, 258-260. http://dx.doi.org/10.1016/j.apnr.2014.03.005

Leitch, J. (2014). Exploring psychometric properties of the interdisciplinary perception scale in health graduate students. Journal of Interprofessional Care, 28(1), 52-57, http://dx.doi.org/10.3109/13561820.2013.820691 
Luecht, R.M., Madsen, M.K., Taugher, M.P., \& Petterson, B.J. (1990). Assessing professional perceptions: Design and validation of an Interdisciplinary Education Perception Scale. Journal of Allied Health, 19(2), 181-191. Retrieved from https://www.researchgate.net/publication/20789727_Assessing_professional_perc eptions_design_and_validation_of_an_Interdisciplinary_Education_Perception_S cale

McFadyen, A.K., Maclaren, W.M., \& Webster, V.S. (2007). The interdisciplinary education perception scale (IEPS): An alternative remodeled sub-scale structure and its reliability. Journal of Interprofessional Care, 21, 433-443. http://dx.doi.org/10.1080/13561820701352531.

Okuda, Y., Bryson, E. O., DeMaria Jr, S., Jacobson, L., Quinones, J., Shen, B., \& Levine, A. (2009). The utility of simulation in medical education: What is the evidence? Mount Sinai Journal of Medicine, 76, 330-343. http://dx.doi.org/10.1002/msj.20127

Poore, J. A., Cullen, D. L., \& Schaar, G. L. (2014). Simulation-based interprofessional education guided by Kolb's experiential learning theory. Clinical Simulation in Nursing, 10(5), e241-e247. http://dx.doi.org/10.10106/j.ecns.2014.01.004.

Scherer, Y.K., Myers, J., O’Connor, T.D., \& Haskins, M. (2013). Interprofessional simulation to foster collaboration between nursing and medical students. Clinical Simulation in Nursing, 9(11), e497-e505. http://dx.doi.org/10.1016/j.ecns.2013.03.001.

Society for Simulation in Healthcare. (2017). About SSH. Retrieved from http://www.ssih.org. 
Taylor, A., Dixon-Hardy, D. W., \& Wright, S. (2014). Simulation training in the U.K. general aviation: An undervalued aid to reducing loss of control accidents. The International Journal of Aviation Psychology, 24(2), 141-152.

http://dx.doi.org/10.1080/10508414.2014.892762.

The Joint Commission. (2016). 2017 Hospital National Patient Safety Goals. Retrieved from https://www.jointcommission.org/hap_2017_npsgs/.

Titzer, J., Swenty, C., \& Hoehn, W. (2012). An interprofessional simulation promoting collaboration and problem solving among nursing and allied health professional students. Clinical Simulation in Nursing, 8(8), e325-e333.

http://dx.doi.org/10.1016/j.ecns.2011.01.001.

Ulrich, B. \& Mancini, B. (2014). Mastering simulation: A handbook for success. Indianapolis: Sigma Theta Tau International. 


\section{Appendix A}

\section{Interdisciplinary Education Perception Scale}

\section{PRE / POST}

Please complete this survey prior to and after your simulation experience.

Mother's date of birth (To allow matching of the pre and post responses): (Month/day)

Using the scale below, (Strongly Disagree-1 to Strongly Agree-6) please rate your perception of your profession and other disciplines.

\begin{tabular}{|c|c|c|c|c|c|c|}
\hline DESCRIPTOR & $\begin{array}{c}\text { Strongly } \\
\text { Disagree } \\
1\end{array}$ & $\begin{array}{l}\text { Moderately } \\
\text { Disagree } \\
2\end{array}$ & $\begin{array}{l}\text { Somewhat } \\
\text { Disagree } \\
3\end{array}$ & $\begin{array}{c}\text { Somewhat } \\
\text { Agree } \\
4\end{array}$ & $\begin{array}{l}\text { Moderately } \\
\text { Agree } \\
5\end{array}$ & $\begin{array}{l}\text { Strongly } \\
\text { Agree } \\
6\end{array}$ \\
\hline $\begin{array}{l}\text { 1. Individuals in my } \\
\text { profession are well- } \\
\text { trained. }\end{array}$ & 1 & 2 & 3 & 4 & 5 & 6 \\
\hline $\begin{array}{l}\text { 2. Individuals in my profession } \\
\text { are able to work closely with } \\
\text { individuals in other professions. }\end{array}$ & 1 & 2 & 3 & 4 & 5 & 6 \\
\hline $\begin{array}{l}\text { 3. Individuals in my profession } \\
\text { demonstrate a great deal of } \\
\text { autonomy. }\end{array}$ & 1 & 2 & 3 & 4 & 5 & 6 \\
\hline $\begin{array}{l}\text { 4. Individuals in other } \\
\text { professions respect the work } \\
\text { done by my profession. }\end{array}$ & 1 & 2 & 3 & 4 & 5 & 6 \\
\hline $\begin{array}{l}\text { 5. Individuals in my profession } \\
\text { are very positive about their } \\
\text { goals and objectives. }\end{array}$ & 1 & 2 & 3 & 4 & 5 & 6 \\
\hline $\begin{array}{l}\text { 6. Individuals in my } \\
\text { profession need to } \\
\text { cooperate with other } \\
\text { professions. }\end{array}$ & 1 & 2 & 3 & 4 & 5 & 6 \\
\hline $\begin{array}{l}\text { 7. Individuals in my } \\
\text { profession are very } \\
\text { positive about their } \\
\text { contributions and } \\
\text { accomplishments. }\end{array}$ & 1 & 2 & 3 & 4 & 5 & 6 \\
\hline $\begin{array}{l}\text { 8. Individuals in my profession } \\
\text { must depend upon the work of } \\
\text { people in other professions. }\end{array}$ & 1 & 2 & 3 & 4 & 5 & 6 \\
\hline $\begin{array}{l}\text { 9. Individuals in other } \\
\text { professions think highly of my } \\
\text { profession. }\end{array}$ & 1 & 2 & 3 & 4 & 5 & 6 \\
\hline $\begin{array}{l}\text { 10. Individuals in my } \\
\text { profession trust each other's } \\
\text { professional judgment. }\end{array}$ & 1 & 2 & 3 & 4 & 5 & 6 \\
\hline $\begin{array}{l}\text { 11. Individuals in my profession } \\
\text { have a higher status than } \\
\text { individuals in other professions. }\end{array}$ & 1 & 2 & 3 & 4 & 5 & 6 \\
\hline $\begin{array}{l}\text { 12. Individuals in my } \\
\text { profession make every effort to } \\
\text { understand the capabilities and } \\
\text { contributions of other }\end{array}$ & 1 & 2 & 3 & 4 & 5 & 6 \\
\hline
\end{tabular}




\begin{tabular}{|l|c|c|c|c|c|c|}
\hline $\begin{array}{l}\text { 13. Individuals in my profession } \\
\text { are extremely competent. }\end{array}$ & 1 & 2 & 3 & 4 & 5 & 6 \\
\hline $\begin{array}{l}\text { 14. Individuals in my } \\
\text { profession are willing to share } \\
\text { information and resources with } \\
\text { other professionals. }\end{array}$ & 1 & 2 & 3 & 4 & 5 & 6 \\
\hline $\begin{array}{l}\text { 15. Individuals in my } \\
\text { profession have good } \\
\text { relations with people in other } \\
\text { professions. }\end{array}$ & 1 & 2 & 3 & 4 & 5 & 6 \\
\hline $\begin{array}{l}\text { 16. Individuals in my profession } \\
\text { think highly of other related } \\
\text { professions. }\end{array}$ & 1 & 2 & 3 & 4 & 5 & 6 \\
\hline $\begin{array}{l}\text { 17. Individuals in my profession } \\
\text { work well with each other. }\end{array}$ & 1 & 2 & 3 & 4 & 5 & 6 \\
\hline $\begin{array}{l}\text { 18. Individuals in other } \\
\text { professions often seek the advice } \\
\text { of people in my profession. }\end{array}$ & 1 & 2 & 3 & 4 & 5 & 6 \\
\hline
\end{tabular}

Student IEPS - Luecht et al, (1990, Journal of Allied Health, 181-191) with permission. 


\section{Appendix B}

\section{Interprofessional Simulation Daily Schedule}

\begin{tabular}{|c|c|}
\hline \multicolumn{2}{|c|}{ Two Groups Schedule } \\
\hline Group A & Group B \\
\hline $\begin{array}{l}\text { 8 AM-830 AM: Orientation of } \\
\text { Nursing students, APRN students } \\
\text { and social work students by their } \\
\text { faculty. The orientation will } \\
\text { include orientation to equipment, } \\
\text { the environment, and medication } \\
\text { location and any pre-simulation } \\
\text { assignments. Cardiopulmonary } \\
\text { Resuscitation (CPR) practice }\end{array}$ & $\begin{array}{l}\text { 8 AM-830 AM: Orientation of } \\
\text { Nursing students, APRN students } \\
\text { and social work students by their } \\
\text { faculty. The orientation will } \\
\text { include orientation to equipment, } \\
\text { the environment, and medication } \\
\text { location and any pre-simulation } \\
\text { assignments. }\end{array}$ \\
\hline $\begin{array}{l}\text { - 830-840 Simulation pre-brief and } \\
\text { research data collection }\end{array}$ & $\begin{array}{l}\text { - 830-840 Simulation pre-brief and } \\
\text { research data collection }\end{array}$ \\
\hline - $\mathbf{8 5 0 - 9 1 5}$ Isaac Morris Simulation & $\begin{array}{l}\text { 840-915 Pre-simulation } \\
\text { assignment review and CPR } \\
\text { practice }\end{array}$ \\
\hline - $\mathbf{9 1 5 - 9 5 0}$ debriefing & $\begin{array}{l}\text { - } \quad \text { 920-945 Isaac Morris Simulation } \\
\text { - } \quad 945-950 \text { bathroom/snack break }\end{array}$ \\
\hline $\begin{array}{l}\text { - } 950-955 \text { brief bathroom/snack } \\
\text { break }\end{array}$ & - 950-1020 debriefing \\
\hline - 955-1015 Esther Smith simulation & $\begin{array}{l}\text { - 1020-1040 Esther Smith } \\
\text { simulation }\end{array}$ \\
\hline - $1020-1040$ debriefing & - 1040-1100 debriefing \\
\hline $\begin{array}{l}\text { - 1045-1110 Trey Anderson } \\
\text { simulation }\end{array}$ & $\begin{array}{l}\text { 1115-1140 Trey Anderson } \\
\text { simulation }\end{array}$ \\
\hline $\begin{array}{l}\text { - } 1110-1135 \text { debriefing } \\
\text { - } 1135-1145 \text { bathroom \& snack } \\
\text { break }\end{array}$ & $\begin{array}{l}\text { - } 1140-1205 \text { debriefing } \\
\text { - } 1205-1215 \text { bathroom \& snack } \\
\text { break }\end{array}$ \\
\hline - 1145-1200 Jason Carter simulation & - 1215-1230 Jason Carter simulation \\
\hline - $\quad$ 1200-1230 debriefing & - 1230-100 debriefing \\
\hline $\begin{array}{l}\text { 1230-1250 evaluation and data } \\
\text { collection for research }\end{array}$ & $\begin{array}{l}\text { - } 1 \text {-120 evaluation and data } \\
\text { collection for research }\end{array}$ \\
\hline $\begin{array}{l}\text { 1250- lunch break (time } \\
\text { determined by faculty) followed } \\
\text { by profession specific debriefing }\end{array}$ & $\begin{array}{l}\text { 120- lunch break (time } \\
\text { determined by faculty) followed } \\
\text { by profession specific debriefing }\end{array}$ \\
\hline
\end{tabular}




\section{Appendix C \\ CONSENT DOCUMENT \\ Rhode Island College \\ Interprofessional Simulation: Students' Perceptions}

You are being asked to be in a research study about your perceptions of interprofessional simulation. You are being asked because you are a participant in the interprofessional simulation activity today at Rhode Island College. Please read this form and ask any questions that you have before choosing whether to be in the study.

Elizabeth Welch, RN, BSN, a student in the Master's program at Rhode Island College, is doing this study. Dr. Debra Servello is serving as the faculty advisor.

\section{Why this Study is Being Done (Purpose)}

The purpose of this study is to examine undergraduate nursing students, graduate social work students, and APRN students' perceptions of one another as healthcare professionals using interdisciplinary simulation.

\section{What You Will Have to Do (Procedures)}

If you choose to be in the study, we will ask you to:

- First, you'll read and answer some survey questions. The Interdisciplinary Education Perception Scale (IEPS) is an 18-question Likert scale questionnaire that measures the effect of interprofessional education experiences on students This will take about 10 minutes.

- Second, after your participation in the day of scheduled day of simulation, you will complete the same survey again, answering the exact same questions that measure the effect of interprofessional education experiences on students This will also take about 10 minutes.

\section{$\underline{\text { Risks or Discomforts }}$}

The risks of participating in this survey are minimal. You may find that you do not want to answer some of the survey questions. You can skip any questions you don't want to answer. I will be available if you would like to discuss the survey after completion. If you feel uncomfortable discussing your thoughts with me, please feel free to contact Dr. Servello at dservello@ric.edu

\section{Benefits of Being in the Study}

Being in this study will not benefit you directly. 


\section{Deciding Whether to Be in the Study}

Being in the study is your choice to make. Nobody can force you to be in the study. You can choose not to be in the study, and nobody will hold it against you. You can change your mind and quit the study at any time, and you do not have to give a reason. If you decide to quit later, nobody will hold it against you.

\section{How Your Information will be Protected}

Because this is a research study, results will be summarized across all participants and shared in results that may be published or presented in the future. Steps will be taken to protect the information that you give so that you cannot be identified. Your mother's birthdate is used to compare pre and posttests only. The completed surveys will be kept in a locked filing cabinet by the researcher and will only be seen by myself and the researchers who work with me. Also, if there are problems with the study, the records may be viewed by the Rhode Island College review board responsible for protecting the rights and safety of people who participate in research. The information will be kept for a minimum of three years after the study is over, after which it will be destroyed.

\section{$\underline{\text { Whom to Contact }}$}

You can ask any questions you have now. If you have any questions later, you can contact me at 401-952-1680 or ewelch_8917@email.ric.edu. You may also contact the faculty supervisor, Debra Servello, at 401-456-9611 or dservello@ ric.edu

If you think you were treated badly in this study, have complaints, or would like to talk to someone other than the researcher about your rights or safety as a research participant, please contact Cindy Padula at IRB@ ric.edu, by phone at 401-456-9720.

You will be given a copy of this form to keep.

\section{Statement of Consent}

I have read and understand the information above. I am choosing to be in the study "Interprofessional Simulation: Students' Perceptions". I understand that by completing the survey and handing it in, my consent to participate is implied. I can change my mind and quit at any time, and I don't have to give a reason. I have been given answers to the questions I asked, or I will contact the researcher with any questions that come up later. I am at least 18 years of age.

Thank you very much for your participation!

Sincerely,

Name of Researcher Obtaining Consent: Elizabeth K. Welch 
Appendix D

\begin{tabular}{|c|c|c|c|c|c|c|c|c|c|c|c|c|c|c|c|c|c|c|}
\hline 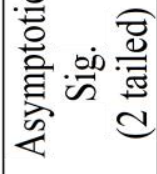 & & : & ¿̊. & ठ̊. & : & $\begin{array}{l}\stackrel{2}{0} \\
\vdots \\
0\end{array}$ & ڤ్. & 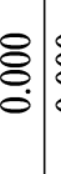 & : & 吾 & ठे. & ठ̊. & ठ & छి. & ஜे & छి. & छి. & ஜ \\
\hline 蒙 菋 & $\mid \begin{array}{l}\bar{n} \\
2 \\
0\end{array}$ & 等. & 它 & 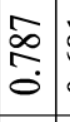 & 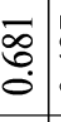 & 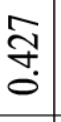 & S. & 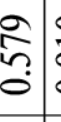 & 遂 & . & 年 & 是 & : & 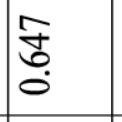 & ஓे & 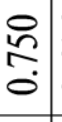 & 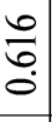 & ळ. \\
\hline 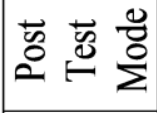 & $n$ & o & $n$ & 0 & 6 & 6 & in & 6. & $n$ & $n$ & $m$ & 6 & in & 0 & 6 & 0 & (o) & $n$ \\
\hline 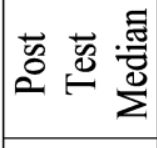 & in & 6 & $n$ & o. & $n$ & 6 & in & 6. & in & $n$ & $\nabla$ & in & in & 0 & 0 & in & 6 & in \\
\hline 范范焉 & $\begin{array}{l}f \\
\sim \\
i\end{array}$ & $\sqrt[n]{n}$ & 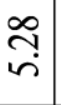 & 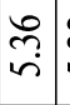 & 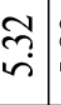 & $\begin{array}{l}\hat{\infty} \\
i \\
i\end{array}$ & $\begin{array}{l}n \\
\tilde{n} \\
\text { n. }\end{array}$ & $\begin{array}{c}8 \\
b \\
i\end{array}$ & s. & ते & rin. & 穵 & $\begin{array}{l}\text { in } \\
\text { in }\end{array}$ & id & $\begin{array}{l}q \\
\dot{i n} \\
:\end{array}$ & $\begin{array}{l}n \\
\tilde{n} \\
i\end{array}$ & 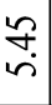 & त్ \\
\hline 总苍倜 & $\mid \begin{array}{c}\infty \\
\infty \\
0 \\
0\end{array}$ & 文 & 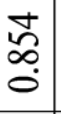 & ڤ్ & 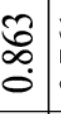 & $\begin{array}{l}\overline{0} \\
\vdots \\
0\end{array}$ & $\begin{array}{l}9 \\
\vdots \\
0 \\
0\end{array}$ & 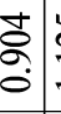 & $\underset{1}{\beth}$ & 离. & 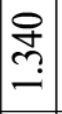 & gे & $\underset{8}{8}$ & \begin{tabular}{|l}
$\tilde{I}$ \\
$\infty$ \\
0 \\
0
\end{tabular} & $\left|\begin{array}{l}2 \\
2 \\
0 \\
0\end{array}\right|$ & $\begin{array}{l}\bar{\approx} \\
0 \\
0\end{array}$ & $\begin{array}{l}\infty \\
\stackrel{0}{0} \\
0\end{array}$ & ఃे \\
\hline 总苞离 & in & $n$ & $n$ & in & $n$ & 6 & $\therefore$ & 6. & $n$ & $n$ & $m$ & in & in & in & in & in & $n$ & in \\
\hline 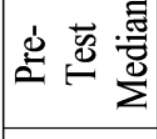 & in & in & $n$ & in & $n$ & ( & $\therefore$ & in & $n$ & $n$ & $m$ & $n$ & in & in & in & in & $n$ & in \\
\hline 总苛歪 & $\begin{array}{l}m \\
i n\end{array}$ & $\begin{array}{l}0 \\
\text { in. }\end{array}$ & $\stackrel{2}{\stackrel{q}{q}}$ & $\underset{\sim}{\stackrel{F}{*}}$ & 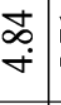 & $\begin{array}{r}\bar{n} \\
\dot{n}\end{array}$ & $\begin{array}{l}\infty \\
\dot{n} \\
\dot{1}\end{array}$ & 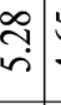 & $\begin{array}{l}\approx \\
+ \\
+\end{array}$ & $\begin{array}{l}\infty \\
+ \\
+\end{array}$ & $\frac{\partial}{m}$ & 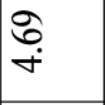 & 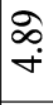 & $\frac{5}{6}$ & $\underset{f}{\sigma}$ & $\underset{+}{\sigma}$ & $\stackrel{n}{a}$ & $\stackrel{\infty}{\underset{f}{*}}$ \\
\hline 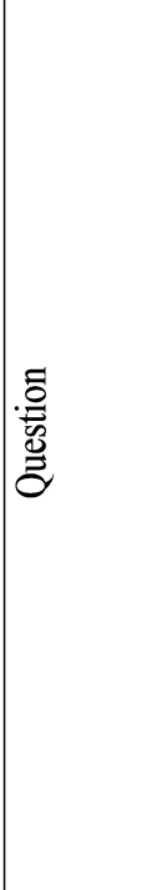 & 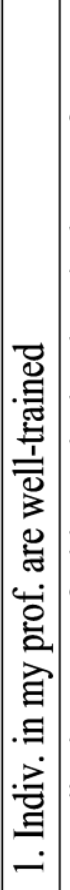 & 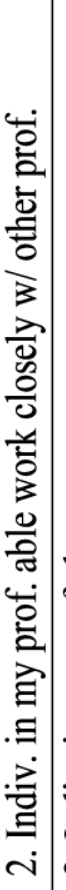 & 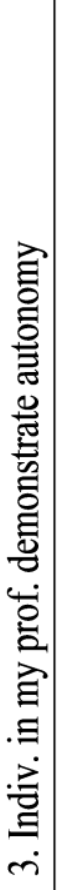 & 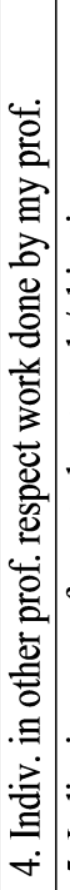 & 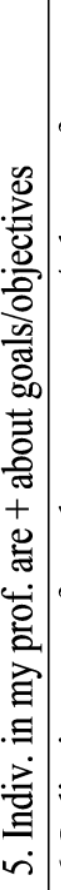 & 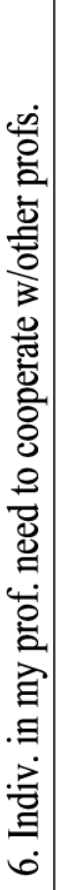 & 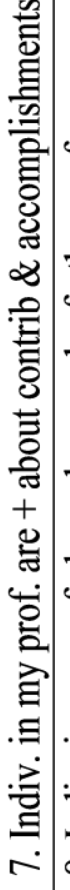 & 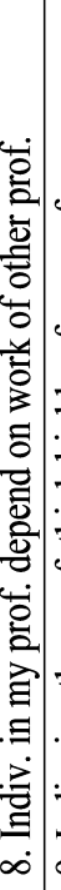 & 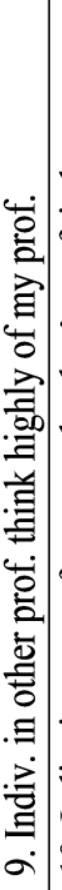 & 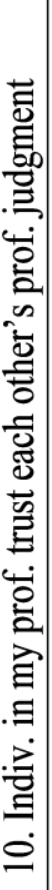 & 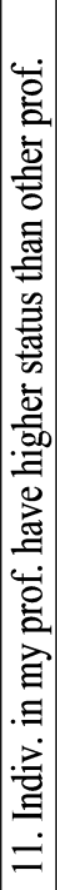 & 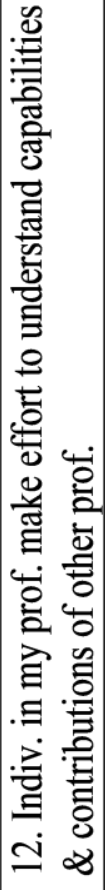 & 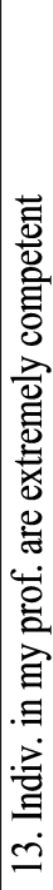 & 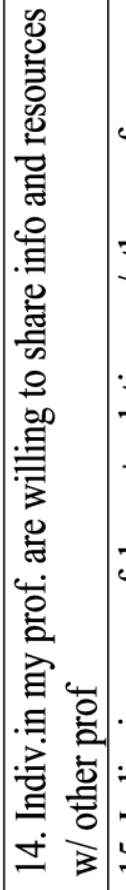 & 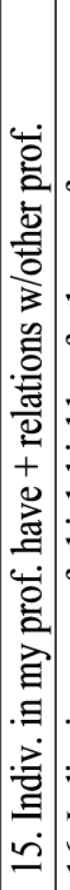 & 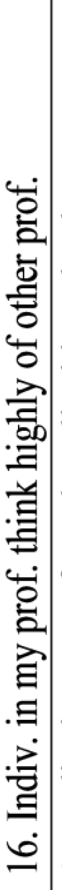 & 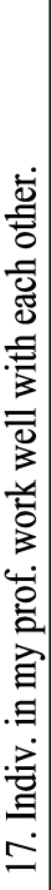 & 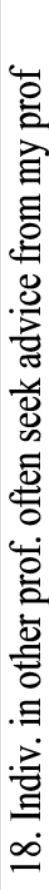 \\
\hline
\end{tabular}

